\title{
A FUNÇÃO DA ANÁLISE OU DO CÁLCULO NA MUDANÇA DA RELAÇÃO SUJEITO-OBJETO
}

\author{
THE FUNCTION OF ANALYSIS OR CALCULUS IN THE SUBJECT-OBJECT RELATIONSHIP
}

\author{
Itamar Soares Veiga* \\ Rafael Müller**
}

\section{RESUMO}

$\mathrm{O}$ artigo trata sobre o tema da transição entre a mathesis e o surgimento do sujeito através da inversão "copernicana" realizada por Kant durante a época moderna. Esta transição é central no livro As palavras e as coisas onde a preocupação com os objetos e seus signos, passa a ser uma preocupação a respeito do conhecimento do sujeito. Diante desse quadro, o foco principal da investigação remete ao cálculo matemático (a Análise) como o elemento metodológico que percorre ambas as fases. Este elemento metodológico é constatado tanto na época da mathesis, onde contribui para ordenar as coisas não-mensuráveis, quanto na época em que surge o sujeito, onde o cálculo contribui como um fator determinante da mudança. A conclusão mostra que a relação do homem com a natureza passa a ser de um mero leitor, a um sujeito ativo, provocador para que a natureza se mostre no que ela é.

PALAVRAS-CHAVE: Mathesis. Coisas não-mensuráveis. Cálculo. Sujeito.

\section{ABSTRACT}

This article discusses the issue of transition between the mathesis and the emergence of the subject through the "copernican" inversion carried out by Kant during modern era. This transition is central in the book The Order of Things where the concern for objects and its signs turns into a concern regarding the subject's knowledge. Given this picture, the main focus of this investigation refers to the mathematical calculation (Analysis) as the methodological element running through both phases. This methodological element is found both during the mathesis period, where it contributes to give order to non-measurable things, as well as during the time when the subject emerges, where math calculation contributes as a

\footnotetext{
* Doutor em filosofia, professor do curso de filosofia da Universidade de Caxias do Sul e do Programa de Pós Graduação da Universidade de Caxias do Sul. Email: inpesquisa@yahoo.com.br.

${ }^{* *}$ Mestrando em filosofia do Programa de Pós-Graduação em Filosofia, strictu sensu, da Universidade de Caxias do Sul. Email: rfamuller@gmail.com.
}

Sapere aude - Belo Horizonte, v. 7 - n. 12, p. 117-131, Jan./Jun. 2016 - ISSN: 2177-6342 
determinant factor for this change. The conclusion shows that man's relationship with nature turns from being a mere reader, to becoming an active subject, one that provokes nature to show itself as it is.

KEYWORDS: Mathesis. Non-measurable things. Calculus. Subject.

\section{INTRODUÇÃO}

Michel Foucault é um autor complexo que possui uma profundidade filosófica que não pode ser desprezada. A sua análise sobre os objetos e sobre como se organizam os sistemas de objetos em As palavras e as coisas mostra a presença de um elemento frequentemente não muito destacado, mas determinante: a Análise ou o cálculo, inventado por Newton e Leibniz.

A Análise permite colocar em prática uma relação assimétrica entre ordem e medida. Assim, se em As palavras e as coisas, os objetos devem se orientar pela mathesis (ciência da ordem e da medida) advém um elemento complicador: a ordem deve ordenar tudo, mesmo as coisas não mensuráveis. Para uma ordenação dessas coisas não mensuráveis, a ferramenta do cálculo é muito valiosa.

Contudo, esta ordenação é um processo e, segundo a análise de Foucault, este processo possui dois momentos ao longo da época moderna: no primeiro momento o foco é o ordenamento das séries de objetos através de seus signos, para construir estas séries se emprega a Análise/cálculo. Neste sentido, a relação com a natureza se estabelece de forma que a natureza oferece uma compreensão do que ela é, de modo que um signo se remeta a outro. Mas, no segundo momento, aprofundando toda a capacidade da Análise ou do cálculo, o ordenamento faz com que a natureza apareça conforme ela é, ou seja, neste segundo momento, a natureza não mais se oferece, mas é provocada a oferecer algo. Tal provocação não somente busca uma resposta empírica e concreta, mas explora também as possibilidades dentro de mundo possíveis descortinados e tornados inteligíveis pela Análise.

Entre o primeiro e o segundo momento, a marca filosófica da mudança é a concepção de sujeito. O sujeito, neste contexto, passa a ser compreendido como resultante da inversão copernicana feita por Kant na Crítica da razão pura.

Este artigo visa destacar o papel da Análise (ou do cálculo) nestes dois momentos da época moderna mostrados em As palavras e as coisas. O objetivo principal é argumentar que

Sapere aude - Belo Horizonte, v. 7 - n. 12, p. 117-131, Jan./Jun. 2016 - ISSN: 2177-6342 
a Análise (ou o cálculo) foi um fator determinante na mudança entre a preferência inicial da busca de uma teoria dos objetos para a inversão e domínio do sujeito sobre o objeto. Sobre este último aspecto, assinala-se que Análise gerou as condições de possibilidade para a compreensão do homem como sujeito e objeto simultaneamente.

Na primeira parte será mostrado o predomínio dos objetos e a procura de uma teoria dos objetos sobre o mundo real. A segunda parte tratará da inversão kantiana entre sujeito e objeto, apontada por Focault como um fator de mudança da relação do homem com os objetos.

A análise de Foucault, na obra As palavras e as coisas, leva em conta uma divisão dentro do que comumente se denomina de época moderna. É uma divisão entre dois períodos. Esta divisão é parte do resultado do método original em uma demonstração da utilização da "arqueologia". Esta divisão, descoberta arqueologicamente, constitui parte da estrutura interna do livro As Palavras e as coisas. Ela é apresentada já no início da obra, mais precisamente no prefácio:

\begin{abstract}
Ora esta investigação arqueológica mostrou duas grandes descontinuidades na episteme da cultura ocidental: aquela que inaugura a idade clássica (por volta dos meados do século XVII) e aquela que, no início do século XIX, marca o limiar de nossa modernidade. A ordem, sobre cujo fundamento pensamos, não tem o mesmo modo de ser que a dos clássicos. Por muito forte que seja a impressão que temos de um movimento quase ininterrupto da ratio européia desde o renascimento até os nossos dias, [...] toda esta quase-continuidade ao nível das idéias e dos temas não passa, certamente, de um efeito de superficie; no nível arqueológico, vê-se que o sistema das positividades mudou de maneira maciça na curva dos séculos XVIII e $X I X$. Não que a razão tenha feito progressos; mas o modo de ser das coisas e da ordem que, distribuindo-as, oferece-as ao saber, é que foi profundamente alterado. [...] Os conhecimentos chegam talvez a se engendrar, a idéias a se transformar e a agir umas sobre as outras (mas como? até o presente os historiadores não no-lo disseram); uma coisa, em todo o caso, é certa: a arqueologia, dirigindo-se ao espaço geral do saber, as suas configurações e ao modo de ser das coisas que aí aparecem, define sistemas de simultaneidade, assim como a série de mutações necessárias e suficientes para circunscrever o limiar de uma positividade nova (FOUCAULT, 1985, p.12, no texto todo, o uso do itálico é do autor).
\end{abstract}

A explicação da divisão de duas fases na época moderna deve ser obtida, por Foucault, através da "arqueologia", mas o que se destaca, principalmente o fim desta citação é o termo "positividade" ou, também, a expressão "sistema de positividades". Nestes destaques se manifestam a opção de Foucault de manter o seu foco de análise sobre as relações do saber 
e do poder. São estas relações que, ao se deterem sobre as "positividades", orientam a sua pesquisa "arqueológica". Além disso, na passagem acima pode ser ainda destacada a importância de não permanecer apenas na "superfície" ou no "efeito de superfície" da "quasecontinuidade". Esta "quase-continuidade" remete à "ordem sob cujo fundamento nós pensamos". É preciso ultrapassar o "efeito de superfície" e alcançar o que realmente mudou. Uma mudança que é identificada no período da "curva dos séculos XVIII-XIX”. O que realmente mudou ficou, então, registrado nos monumentos mudos deixados na história. E, este registro foi feito pelos "sistemas de positividades". Foucault, ao pesquisar arqueologicamente estes monumentos mudos, percebe a época moderna dividida em duas fases.

$\mathrm{Na}$ primeira fase da época moderna, o sistema de positividades trabalha sobre os signos e procura ordená-los e medi-los. Ou seja, a ordem e medida são os elementos abstratos mais importantes que regulam a compreensão do mundo e direcionam as ações dos sistemas de positividades. Assim, tais sistemas geram os seus resultados na forma de registros escritos, manuais, etc. Como se expressa a conjunção interna destes dois elementos abstratos: a ordem e a medida? É razoável supor que ambos os elementos se conjugam ou guardam entre si uma relação, pois agem em conjunto sobre os objetos. A sua conjugação transparece na definição da mathesis.

Foucault caracteriza a primeira fase da época moderna, ou melhor, a época moderna até o final do século XVIII, como período da ênfase do papel da ordem e da medida ${ }^{1}$. Estes dois elementos abstratos da mathesis são transpostos para a ação no mundo efetivo. Mas, para conseguir esta transposição é preciso um método que trabalhe os signos, a partir dois quais os objetos se mostram e a natureza se mostra, oferecendo aos homens uma compreensão. Este método, o mais aperfeiçoado deles, é a Análise ou cálculo. Ao mencionar o método da Análise, Foucault se refere ao projeto leibniziano de uma matemática das ordens qualitativas. Essas afirmações estão articuladas na seguinte passagem:

[...]. Pois o fundamental, para a epistémê clássica, não é nem o sucesso ou o fracasso do mecanicismo, nem o direito ou a impossibilidade de matematizar a natureza, mas sim uma relação com a máthêsis que, até o fim do século XVIII, permanece constante e inalterada. Essa relação apresenta dois caracteres essenciais. O primeiro é que as relações entre os seres serão realmente pensadas sob a forma da ordem e da medida, mas com este desequilíbrio fundamental de se poderem sempre reduzir os

\footnotetext{
${ }^{1}$ Os elementos da ordem e da medida, vinculados à mathesis, podem ser vistos nas Regras para a condução do espírito, IV, de Descartes.
}

Sapere aude - Belo Horizonte, v. 7 - n. 12, p. 117-131, Jan./Jun. 2016 - ISSN: 2177-6342 
problemas da medida aos da ordem. De sorte que a relação de todo conhecimento com a máthêsis se oferece como a possibilidade de estabelecer entre as coisas, mesmo não-mensuráveis, uma sucessão ordenada. Nesse sentido, a análise vai adquirir bem depressa valor de método universal; e o projeto leibniziano de estabelecer uma matemática das ordens qualitativas se acha no coração mesmo do pensamento clássico; é em torno dele que gravita todo esse pensamento. (FOUCAULT, 1985, p.72).

O principal aspecto dentro do quadro geral é a menção deste "desequilíbrio fundamental" que os problemas da medida se submetem à ordem. Um desses problemas é aquela das coisas "não-mensuráveis", ou coisas que escapam da medida. Esta submissão é uma redução, e tal redução não significa tornar exatamente medido aquilo que era nãomensurável. Diante do problema das coisas não-mensuráveis, a redução ordenadora se estende até o extremo e alcança o infinito. Para cumprir este papel, está presente o inovador recurso do cálculo. Independente da disputa autoral entre Newton e Leibniz, o cálculo trabalha com as dimensões infinitamente pequenas ou o "infinitésimo" e com as possibilidades, que tendem ao infinito, de fornecer áreas ou pontos precisos em uma curvatura. Assim, se o ordenamento da de todas as coisas, inclusive daquelas "não mensuráveis", valoriza o ordem, colocando tudo em séries, então, utiliza-se o cálculo integral ou o cálculo de derivadas ${ }^{2}$.

Como exemplo pode-se calcular formas não tem uma curvatura, tais como quadrado, o retângulo e o triângulo e semelhantes, com precisão. Pode-se, também, calcular a área de um círculo (onde o fator de imprecisão permanecerá no número de casas depois da vírgula da constante $P I)$. A fórmula para o cálculo da área de um círculo é: PI multiplicado pelo Raio elevado ao quadrado: $\Pi r^{2}$.

Mas, certas coisas do mundo real não são mensuráveis porque possuem curvaturas ou sinuosidades, como elas podem ser calculadas? Uma curvatura ou sinuosidade é uma incompletude, que não perfaz um círculo perfeito e, portanto, a fórmula não pode ser a mesma daquela do círculo PI. Eis uma representação gráfica de uma destas formas:

\footnotetext{
${ }^{2}$ Neste artigo, e a respeito desse assunto do ordenamento de coisas "não mensuráveis", forneceremos um exemplo apenas a partir da Integral e seu gráfico, um conhecimento básico, visual de cálculo. Não nos determos na Derivada, contudo, o mesmo papel exemplificador poderia ser cumprido por esta. A Derivada fornece uma informação do detalhe, no entanto, o foco permaneceu na Integral, porque a percepção sensível de "coisas nãomensuráveis" é mais intuitiva, do que os detalhes ínfimos.
}

Sapere aude - Belo Horizonte, v. 7 - n. 12, p. 117-131, Jan./Jun. 2016 - ISSN: 2177-6342 


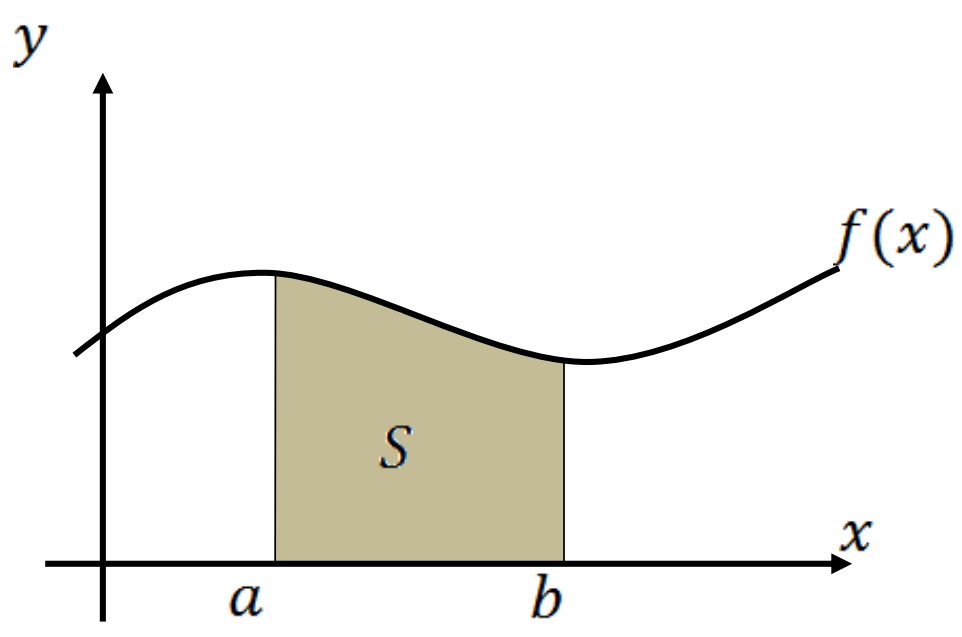

Assim, compreende-se também matematicamente o contexto visado Foucault quando, na citação mais acima refere que: "a análise vai adquirir bem depressa valor de método universal; e o projeto leibniziano de estabelecer uma matemática das ordens qualitativas se acha no coração mesmo do pensamento clássico.” Na preocupação com a ordenação das coisas não-mensuráveis, Leibniz vai se deslocar para a metafísica. No trecho abaixo, Paolo Rossi, cita encaminhamento de Leibniz para a metafísica, sendo que esta não era o seu objetivo inicial:

Na perspectiva de Leibniz o cartesianismo se configura como materialismo. Após terminar as escolas primárias - escreveria Leibniz em uma carta autobiográfica de 1714 - encontrei-me com os filósofos modernos: "Lembro que, com a idade de quinze anos, fui passear sozinho em um pequeno bosque não distante de Lipcia discutindo comigo mesmo se teria que adotar a teoria das formas substanciais. No fim, a disputa foi vencida pelo mecanicismo e isso me levou em direção das matemáticas. [...] Todavia, na busca das bases mais profundas do mecanicismo e das leis do movimento, voltei para a metafísica e para a doutrina das enteléquias" [Leibniz, 1875-90: III, 606]. Esse retorno a metafísica era fadado a ter uma extraordinária importância nos desenvolvimentos da matemática, da física e da biologia. A partir daí, junto com o cartesianismo e o newtonianismo, o leibnizianismo seria uma das grandes metafísicas que influíram a ciência durante todo o século XVIII e além disso. (ROSSI, 2001, p. 264-265).

Rossi, que é um historiador da filosofia da ciência, afirma que os principais personagens da época de Leibniz, os "novos personagens" ou “filósofos modernos", possuíam um outro tipo de conhecimento. Este conhecimento articulava-se em centros de poder e exigia uma modificação de tais centros de poder. Alguns centros de poder, como a Universidades, eram considerados ultrapassados: 
No Ocidente, as figuras dominantes no mundo da cultura, durante uns mil anos (quer dizer ao longo de dez séculos da Idade Media) são o santo, o monge, o médico, o professor universitário, o militar, o artesão e o mágico. Mais tarde ao lado dessas figuras acrescentam-se aquelas do humanista e do fidalgo da corte. No período que vai de meados do século XVI ate meados do século XVII aparecem outros personagens novos: o mecânico, o filósofo naturalista, o artista virtuoso ou livre empreendedor. Os objetivos perseguidos por tais personagens novos não são a santidade, a imortalidade literária, ou a realização de milagres capazes de encantar o povão. Além disso, o novo saber científico nasce no terreno de uma áspera polêmica contra o saber dos monges, dos escolásticos, dos humanistas e dos professores. Por isso, em 1640, em uma moção dirigida ao Parlamento, Jolin Hall escreve que nas universidades não se ensinam nem a química, nem a anatomia, nem as línguas, nem os experimentos. [...] Uma forte oposição ao saber secreto dos mágicos e dos alquimistas emerge, agora, não tanto do mundo dos filósofos, mas antes do mundo dos engenheiros e dos mecânicos. (ROSSI, 2001, p.53-54).

Os novos personagens são os engenheiros, os mecânicos, os filósofos naturalistas, os artistas. Para estes novos personagens, o uso do método da Análise (ou do cálculo) é um forte estímulo para aprofundar o estudo dos signos e com eles dos objetos. Mesmo que o método da Análise tenha estes elementos metafísicos como se mostrou na citação mais acima sobre Leibniz.

A mathesis é uma ciência que gera uma perspectiva geral e permite um desenvolvimento de vários aspectos da realidade clássica e moderna, sendo que tais aspectos não precisam estar necessariamente vinculados à matematização. Basicamente, a mathesis sustenta a expansão de um ordenamento sobre os vários âmbitos da realidade. A matematização é algo que se conjuga com o surgimento do método da Análise. Mas, a própria Análise vai, de alguma maneira, contra o conhecimento intuitivo geral da matemática, ao ordenar e providenciar uma medida para tudo, inclusive para sinuosidades de coisas nãomensuráveis. Foucault destaca a função de "ciência geral da ordem", da mathesis, com as seguintes palavras:

Por outro lado, porém, essa relação com a máthêsis como ciência geral da ordem não significa uma absorção do saber nas matemáticas nem que nelas se fundamente todo o conhecimento possível; ao contrário, em correlação com a busca de uma máthêsis, vê-se aparecer um certo número de domínios empíricos que até então não tinham sido nem formados, nem definidos. Em nenhum desses domínios ou em quase nenhum é possível encontrar vestígios de um mecanicismo ou de uma matematização; e, contudo, eles se constituíram todos tendo por base uma ciência possível da ordem. Se eles dependiam efetivamente da Análise em geral, seu instrumento particular não era o método algébrico, mas o sistema de signos. Assim apareceram a gramática geral, a história natural, a análise das riquezas, ciências da ordem e no domínio das palavras, dos seres e das necessidades; e todas essas empiricidades, novas na época clássica e co-extensivas à sua duração (têm por pontos de referência cronológicos Lancelot e Bopp, Ray e Cuvier, Petry e Ricardo, que escreveram, os primeiros por volta de 1660, e os segundos por volta dos anos

Sapere aude - Belo Horizonte, v. 7 - n. 12, p. 117-131, Jan./Jun. 2016 - ISSN: 2177-6342 
1800-1810), não se puderam constituir sem a relação que toda a epistémê da cultura ocidental manteve então com uma ciência universal da ordem. (FOUCAULT, 1985, p.72-73).

A "ciência geral da ordem" se torna uma base para diversas descobertas e iniciativas. Entre tais iniciativas estão as novas "empiricidades", as quais tinham como objeto de estudo das atividades humanas como a "gramática geral", a "história natural" e a "análise das riquezas", mencionadas por Foucault. Assim, o processo que se afasta da interpretação hermenêutica dos renascentistas, voltando-se ao estudo do signo, na procura do objeto através do signo, encontra este recurso poderoso disponibilizado por Leibniz e Newton. O uso da Análise estava em curso e evoluindo através das novas empiricidades. Mas, o pano de fundo sustentador ainda era o "sistema de objetos", a Análise era apenas seu "instrumento particular". O objetivo era refletir tal sistema de objetos, maximamente aperfeiçoado, dentro da mathesis, enquanto esta era a "ciência possível da ordem".

Mas este processo de assumir o sistema de objetos como instrumento particular na compreensão dos diversos aspectos do mundo real, se modificou em uma transposição para outro âmbito. E, esta modificação assinala a passagem para a segunda fase da época moderna. O poder matemático da Análise, que permitia ordenar mesmo as coisas não-mensuráveis, se aprofundou a ponto de ir além do próprio sistema de objetos. A Análise mostrou que poderia funcionar também no âmbito da ordenação do que era ou não possível.

No apêndice à primeira edição de Michel Foucault - uma trajetória filosófica - para além do estruturalismo e da hermenêutica, de H. Dreifus e P. Rabinow, o próprio Foucault (em seu escrito: $O$ sujeito e o poder) afirma:

\footnotetext{
Será preciso uma teoria do poder? Uma vez que uma teoria assume uma objetivação prévia, não pode ser afirmada como uma base para um trabalho analítico. Porém, esse trabalho analítico não pode proceder sem uma conceituação em andamento, conceituação essa que implica um pensamento crítico - uma verificação constante. A primeira coisa a verificar é o que eu deveria chamar de "necessidades conceituais". Compreendo que a conceituação não deveria estar fundada em uma teoria do objeto - objeto conceituado não é o único critério de uma boa conceituação. Temos de conhecer as condições históricas que motivam a nossa conceituação. Necessitamos de uma consciência histórica da situação presente. (FOUCAULT, 2010, p.274).
}

As conseqüências da insuficiência de uma teoria de objetos servem apenas como explicação da evolução da trajetória filosófica de Foucault, e, também, reforçam a ultrapassagem dessa necessidade de uma teoria dos objetos. Ao ultrapassar a hegemonia da 
mathesis, e expandir o ordenamento para a proximidade com o homem, o sujeito não permanece apenas mais um objeto entre outros objetos, mas agora ele é uma junção, uma junção entre objeto e sujeito. O sujeito como aquele que comanda o ato do connheicmento e emite juízos.

$\mathrm{Na}$ junção com objeto, o sujeito se preserva como sujeito e se constitui o vetor de racionalidade da segunda fase na época moderna. Esta segunda fase tem como característica a inversão paradigmática promovida por Kant na Crítica da razão pura. Mas, é preciso lembrar as "positividades" empíricas que estavam envolvidas no método da Análise de ordenar mesmo as coisas não-mensuráveis. Estas positividades se coagularam em figuras humanas do mecânico, do engenheiro, do filósofo naturalista, etc. Estes mesmos que deixaram como legados: manuais e outros registros, coletados por Foucault. O modo ocorre esta mudança do objeto para o sujeito, será tratado na próxima parte.

\title{
II
}

Afirma-se que Kant realizou uma "revolução copernicana" no conhecimento, ao propor que o conhecimento não deveria se regular pelos objetos, mas sim a partir do sujeito. Isto é explícito em um pequeno trecho da Crítica da razão pura, o qual se cita como marco inicial de análise:

\begin{abstract}
Até hoje admitia-se que o nosso conhecimento se devia regular pelos objetos; porém, todas as tentativas para descobrir a priori, mediante conceitos, algo que ampliasse o nosso conhecimento, malogravam-se com este pressuposto. Tentemos, pois, uma vez, experimentar se não se resolverão melhor as tarefas da metafísica, admitindo que os objetos se deveriam regular pelo nosso conhecimento, o que assim já concorda melhor com o que desejamos, a saber, a possibilidade de um conhecimento a priori desses objetos, que estabeleça algo sobre eles antes de nos serem dados. Trata-se aqui de uma semelhança com a primeira idéia de Copérnico; não podendo prosseguir na explicação dos movimentos celestes enquanto admitia que toda a multidão de estrelas se movia em torno do espectador, tentou se não daria melhor resultado fazer antes girar o espectador e deixar os astros imóveis. Ora, na metafísica, pode-se tentar o mesmo, no que diz respeito à intuição dos objetos. Se a intuição tivesse de se guiar pela natureza dos objetos, não vejo como deles se poderia conhecer algo a priori; se, pelo contrário, o objeto (enquanto objeto dos sentidos) se guiar pela natureza da nossa faculdade de intuição, posso perfeitamente representar essa possibilidade. (KANT, 2001, p. 45-46).
\end{abstract}

O conhecimento a priori dos objetos pode ser explicitado pelo "instrumento particular" (FOUCAULT, 1985, p. 72) denominado Análise ou cálculo. Este "instrumento 
particular" permite o ordenamento a priori de todos os objetos, pois inclui tanto os objetos mensuráveis quanto os não-mensuráveis. A complexidade do mundo real, onde atuam os homens possuem ambos os tipos de objetos. Assim, nessa complexidade, se destaca aqueles que empregam a Análise como método geral de ordenamento. Através do método geral da Análise, o sujeito regula o conhecimento dos objetos e o faz a priori.

O modo do sujeito era passivo no período anterior do conhecimento do sistema de objetos. Neste processo, conforme Foucault comenta na citação mais abaixo, o ser humano possuía um papel apenas secundário:

\begin{abstract}
Essa relação com a Ordem é tão essencial para toda idade clássica quanto foi para o Renascimento a relação com a Interpretação. E assim como a interpretação do século XVI, superpondo uma semiologia a uma hermenêutica, era essencialmente um conhecimento da similitude, assim a colocação em ordem por meio dos signos constitui todos os saberes empíricos como saberes da identidade e da diferença. O mundo, a um tempo indefinido e fechado, pleno e tautológico, da semelhança se acha dissociado e como que aberto em seu centro; numa extremidade, encontrar-seão os signos tornados instrumentos da análise, marcas da identidade e da diferença, princípios da colocação em ordem, chaves para uma taxionomia; e na outra, a semelhança empírica e murmurante das coisas, essa similitude surda que, por sob o pensamento, fornece a matéria infinita das repartições e das distribuições. De um lado, a teoria geral dos signos, das divisões e das classificações; de outro, o problema das semelhanças imediatas, do movimento espontâneo da imaginação, das repetições da natureza. Entre os dois, os saberes novos que encontram seu espaço nessa distância aberta. (FOUCAULT, 1985, p. 73).
\end{abstract}

O século XVI assinalaria uma mudança importante no que diz respeito ao ordenamento das coisas: a superposição de uma semiologia contra a hermenêutica renascentista. A preocupação com os signos e com o uso dos mesmos para a explicação da semelhança e da similitude encontra-se com descoberta do método geral da Análise. A partir do cálculo, dentro do projeto leibniziano ${ }^{3}$, a "semelhança empírica" e a "similitude surda", alcançam a sua expressão na execução de séries que expressam a "matéria infinita das repartições e das distribuições".

O modo de compreensão do real se afirmaria, assim, no espaço aberto entre a superposição da semiologia sobre a hermenêutica (a interpretação renascentista) e os problemas da medida. Os mesmos problemas que deveriam ser reduzidos à ordem (conforme

\footnotetext{
${ }^{3} \mathrm{O}$ cálculo no continente europeu sofreu mais influência de Leibniz do que de Newton. As dificuldades da disseminação do cálculo originariamente newtoniano são analisadas na obra de Paolo Casini: Newton e a consciência européia, 1995. Leibniz publicou o seu primeiro artigo sobre o cálculo em 1684 e, a relutância de Newton, fez com que a sua criação (mostrada muitos anos antes à Leibniz) fosse publicada somente em 1693.
}

Sapere aude - Belo Horizonte, v. 7 - n. 12, p. 117-131, Jan./Jun. 2016 - ISSN: 2177-6342 
citação de Foucault na primeira parte). Na forma real destes problemas está complexidade do mundo: como calcular a área de uma superfície sinuosa? Ou seja, o espaço aberto aos mecânicos e aos engenheiros era garantido, por um lado pelo afastamento em relação aos interpretadores humanistas (legado renascentista) e, pelo outro lado, pela resolução dos problemas complexos e práticos do mundo (como calcular a área de um terreno sinuoso?). Isto permitiu um emprego ainda maior da Análise, embora nessa primeira fase ela oscilasse nos limites de uma "teoria geral dos signos" e o "movimento espontâneo da imaginação, das repetições da natureza".

Mas, Foucault visa a mudança no âmbito dos saberes, incluindo o caráter abstrato e, principalmente, o registro de um saber como testemunho mudo assinalado no mundo real. Para expor os elementos básicos dessa mudança, onde se confirma a importância de um caráter a priori do conhecimento, em As palavras e as coisas tem-se que:

\begin{abstract}
Uma vez que é sempre certo ou provável, o signo deve encontrar o seu espaço no interior do conhecimento. No século XVI considerava-se que os signos tinham sido depositados sobre as coisas para que os homens pudessem desvendar os seus segredos, a sua natureza ou as suas virtudes; mas essa descoberta nada mais era do que o fim último dos signos, a justificação de sua presença; era sua utilização possível, a melhor, sem dúvida; mas não tinha necessidade de serem conhecidos para existirem: mesmo se permanecessem silenciosos e ninguém e jamais alguém os percebesse, jamais perdiam de sua consistência. Não era o conhecimento, mas a linguagem mesma das coisas que os instaurava na sua função significante. A partir do século XVII, todo o domínio do signo se distribui entre o certo e o provável: isto quer dizer que não seria mais possível haver signo desconhecido, marca muda. Não que os homens estejam de posse de todos os signos possíveis. Mas, sim, que só há um signo a partir do momento em que se acha conhecida a possibilidade de uma relação de substituição entre dois elementos já conhecidos. O signo não espera silenciosamente a vinda daquele que pode reconhecê-lo: ele só se constitui por um ato de conhecimento. (FOUCAULT, 1985, p.74).
\end{abstract}

Encontrar essa "linguagem mesma das coisas" era o objetivo das diversas teorias dos objetos, através dos estudos dos signos, para as quais, a nova ferramenta de estudo: a Análise era uma grande contribuição. Mas, o caráter do "certo" e do "possível” no "domínio do signo", assinala uma mudança. Esta mudança ocorre também em função da prática do método geral da Análise (cálculo), ao ordenar as coisas não mensuráveis. Pois com o novo método, torna-se possível conhecer antecipadamente a possibilidade a respeito dos objetos, sejam eles mensuráveis ou não. Em outras palavras: "só há um signo a partir do momento em que se acha conhecida a possibilidade de uma relação de substituição entre dois elementos já conhecidos" (citação supra). 
Outro elemento muito importante na citação acima é que, para ocorrer o conhecimento do objeto, é necessário um "ato de conhecimento". Isto é, é necessária uma atividade em oposição a mera passividade do objeto. A necessidade de ser ativo incumbe o sujeito de uma tarefa. Contudo, o próprio sujeito, na fase em que predominou a busca por uma teoria dos objetos, era também, não um sujeito, mas um mero objeto no quadro da criação.

Agora, entretanto, o sujeito exerce o seu "ato de conhecimento", ele não é mais meramente um objeto, mesmo que seja algo não-mensurável e algo que possa ser submetido à Análise. Mas, na utilização do método geral da Análise, no cálculo das derivadas e das integrais, é necessário um sujeito. Assim, diante do objeto e, principalmente, diante do signo do objeto, o sujeito é aquele "que pode reconhecê-lo, só ele se constitui por um ato de conhecimento" (citação supra).

Duas passagens de As palavras e as coisas mostram a presença da Análise como o elemento básico que permitiu a transição de uma fase a outra na época moderna. A primeira passagem retoma a discussão sobre a origem dos signos: eles são dados por natureza ou por convenção. Destaca-se que o aspecto convencional dos signos é aquele que predominará:

\begin{abstract}
Resta uma terceira variável: a que pode assumir os dois valores da natureza e da convenção. Sabia-se desde há muito - e bem antes do Crátilo - que os signos podem ser dados pela natureza ou constituídos pelo homem. O século XVI também não o ignorava e reconhecia nas línguas humanas os signos de instituição. Mas os signos artificiais só deviam seu poder á sua fidelidade aos signos naturais. Estes, de longe, fundavam todos os outros. A partir do século XVII, dá-se um valor inverso à natureza e à convenção: natural, o signo não é mais do que um elemento subtraído às coisas e constituído como signo pelo conhecimento. Ele é, pois, prescrito, rígido, incômodo e o espírito não pode assenhorar-se dele. Ao contrário, quando se estabelece um signo de convenção, pode-se sempre (e é preciso, com efeito) escolhê-lo de tal sorte que ele seja simples, fácil de lembrar, aplicável a um número indefinido de elementos, suscetível de se dividir ele próprio e de se compor; o signo de instituição é o signo na plenitude de seu funcionamento. É ele que traça a divisória entre o homem e o animal; ele que transforma a imaginação em memória voluntária, a atenção espontânea em reflexão, o instinto em conhecimento racional. Foi a sua carência ainda que Itard descobriu no "Selvagem de Aveyron". Desses signos de convenção, os signos naturais não passam do esboço rudimentar, o desenho longínquo que só será concluído pela instauração do arbitrário. (FOUCAULT, 1985, p.76-77).
\end{abstract}

Esta variável que pode assumir "os dois valores da natureza e da convenção" é o homem. O homem que, desde Kant, pode assumir a posição ativa no conhecimento e, com isso, analisar (ou calcular) até as coisas não-mensuráveis, inclusive aquelas que possuem o estatuto de serem apenas possíveis. A ligação entre o homem e os objetos, antes da invenção do cálculo, era dada apenas por uma "fidelidade" dos "signos artificiais" com os "signos 
naturais". A partir do século XVII surge a possibilidade de constituir "o signo pelo conhecimento": a "instauração do arbitrário" diferente dos "signos naturais", considerados, a partir de então, apenas um "esboço rudimentar".

A influência da Análise está em que, a partir de sua invenção por Newton e Leibniz, o signo é "fácil de lembrar, aplicável a um número indefinido de elementos, suscetível de se dividir ele próprio e de se compor; o signo de instituição é o signo na plenitude de seu funcionamento" (citação supra). E, este "funcionamento" do signo está vinculado às relações de poder que estão presentes na época de seu surgimento e são agregadas ao próprio recurso metodológico provido pela Análise, tomando-a como o seu "instrumento particular".

A segunda passagem a ser citada abaixo, mostra que, no confronto entre o artificial e o natural, há uma ambigüidade e uma ausência de ambigüidade. Ou seja, no "arbitrário" da construção artificial de signos, Análise vai estabelecer um espaço onde a "natureza vai se oferecer no que ela é". E, por outro lado, onde não há ambigüidade e nem contradição, a Análise, fará: "fazer aparecer a natureza desde seus elementos de origem até a simultaneidade de todas as suas combinações possíveis". Estes destaques estão no seguinte trecho de $A s$ palavras e as coisas:

Mas esse arbitrário é medido por sua função, e suas regras muito exatamente definidas por ela. Um sistema arbitrário de signos deve permitir a análise das coisas nos seus mais simples elementos; deve decompor até a origem; mas deve também mostrar como são possíveis combinações desses elementos e permitir a gênese ideal na complexidade das coisas. "Arbitrário" só se opõe a "natural" se se quiser designar a maneira como os signos foram estabelecidos. Mas o arbitrário é também o crivo de análise e o espaço combinatório através dos quais a natureza vai se oferecer no que ela é ao nível das impressões originárias e em todas as formas possíveis de sua combinação. Na sua perfeição, o sistema dos signos é essa língua simples, absolutamente transparente, que é capaz de nomear o elementar; é também esse conjunto de operações que define todas as conjunções possíveis. A nossos olhos, essa busca da origem e esse cálculo dos agrupamentos parecem incompatíveis e nós os explicamos facilmente como uma ambigüidade no pensamento dos séculos XVII e XVIII. O mesmo ocorre com o jogo entre o sistema e a natureza. De fato, não há para esse pensamento nenhuma contradição. Mais precisamente, existe uma disposição necessária e única que atravessa toda a epistémê clássica: é a pertença de um cálculo universal e de uma busca do elementar a um sistema que é artificial e que, por isso mesmo, pode fazer aparecer a natureza desde seus elementos de origem até a simultaneidade de todas as suas combinações possíveis. Na idade clássica, servir-se de signos não é, como nos séculos precedentes, tentar reencontrar pó sob eles o texto primitivo de um discurso afirmado, para sempre; é tentar descobrir a linguagem arbitrária que autorizará o desdobramento da natureza no seu espaço, os termos últimos de sua análise e as leis de sua composição. O saber não tem mais que desencravar a velha Palavra dos lugares desconhecidos onde ela se pode esconder; cumpre-lhe fabricar uma língua e que ela seja bem feita - isto é, que, analisante, ela seja realmente a língua dos cálculos. (FOUCAULT, 1985, p.77-78).

Sapere aude - Belo Horizonte, v. 7 - n. 12, p. 117-131, Jan./Jun. 2016 - ISSN: 2177-6342 
Finalmente, neste contexto de mudança e a partir do recurso da Análise, o homem se torna sujeito, tornando-se também objeto de estudo por parte de si mesmo. É isto que afirmam Dreifus e Rabinow na obra sobre a trajetória de Foucault:

\begin{abstract}
O homem, conforme compreendemos hoje, aparece na mudança essencial com a qual estamos preocupados, tornando-se a medida de todas as coisas. Uma vez que a ordem do mundo não é mais dada por Deus, nem passível de ser representada no quadro, quebra-se a contínua relação que colocou o homem lado a lado com os outros seres do mundo. $\mathrm{O}$ homem, que era um ser entre outros, torna-se agora um sujeito entre objetos. Mas, o Homem não é apenas sujeito entre objetos; ele logo entende aquilo que tenta compreender não são apenas os objetos do mundo, mas ele próprio. O homem se torna sujeito e objeto de sua própria compreensão. (DREIFUS; RABINOW, 2010, p.35).
\end{abstract}

É possível ainda fazer uma aproximação com outros textos de Focault depois da sua mudança metodológica, onde o eixo da arqueologia dos saberes converge para o eixo da genealogia. No livro Vigiar e punir, posterior ao livro As palavras e as coisas e cujo tema principal é o poder, Foucault afirma:

\begin{abstract}
A minúcia dos regulamentos, o olhar esmiuçante das inspeções, o controle das mínimas parcelas da vida e do corpo darão em breve, no quadro da escola, do quartel, do hospital ou da oficina, um conteúdo laicizado, uma racionalidade econômica ou técnica a esse cálculo místico do ínfimo e do infinito.[...]

Uma observação minuciosa do detalhe, e ao mesmo tempo um enfoque político dessas pequenas coisas, para controle e utilização dos homens, sobem através da era clássica, levando consigo todo um conjunto de técnicas, todo um corpo de processos e de saber, de descrições, de receitas e dados. E desses esmiuçamentos, sem dúvida, nasceu o homem do humanismo moderno. (FOUCAULT, 1997, p.121).
\end{abstract}

Esta referência ao "cálculo místico do ínfimo e do infinito" podem ser justamente uma referência ao infinitésimo e, portanto, uma referência à metafísica de Leibniz. Enfim, esta seção do artigo mostrou como a Análise (ou o cálculo) está imbricada com as mudanças na época moderna. Nesta mudança, surge o sujeito, explicitado na inversão proporcionada por Kant. O sujeito teve um papel norteador filosoficamente decisivo e socialmente determinante.

\title{
CONCLUSÕES
}

O método da Análise ou do cálculo interferiu na primeira e na segunda parte da época moderna, sendo que no primeiro período a preocupação era suplantar a interpretação hermenêutica renascentista através de uma valorização do signo e, portanto, através de uma 
valorização das teorias sobre os objetos. No segundo período da época moderna aconteceu um aprofundamento dos recursos utilizados. O recurso da Análise foi valorizado. O método geral de Análise ou cálculo, criado por Leibniz e Newton, que permitiu a necessária ordenação das coisas não-mensuráveis. Desta forma, a relação do homem com a natureza mudou, passando de uma forma passiva para uma forma ativa, antes a natureza se mostrava, agora o homem faz com que ela se mostre. Ao aprofundar o recurso propiciado pela Análise, a natureza passou a ser provocada para oferecer a verdade do objeto. Esta provocação além de se situar no âmbito real e empírico, se estendia também para o âmbito da possibilidade. Assim, o homem assumia não mais apenas o estatuto de objeto no quadro da criação, mas era também sujeito.

Percebe-se, portanto, que Análise ou cálculo possui um papel destacado e determinante nos dois períodos da época moderna, permitindo ao homem aprofundar o quadro semiótico e, após a inversão kantiana, se consolidar como sujeito que ordena a todos os objetos, mesmo os não-mensuráveis. Entre estes últimos estão o próprio homem e as suas atividades, ou os elementos para nascerem as ciências humanas.

\section{REFERÊNCIAS}

CASINI, Paolo. Newton e a consciência européia. Tradução R. L. Ferreira. São Paulo: Editora da Universidade Estadual Paulista, 1995.

DREYFUS, Hubert L.; RABINOW, Paul. Michel Foucault, uma trajetória filosófica: para além do estruturalismo e da hermenêutica. Tradução V. Portocarreo, G. G. Carneiro. Rio de Janeiro: Forense Universitária, 2010.

FOUCAULT, Michel. As palavras e a coisas: uma arqueologia das ciências humanas. Tradução S. T. Muchail. São Paulo,: Martins Fontes, 1985. $3^{\mathrm{a}}$ ed.

FOUCAULT, Michel. Vigiar e punir: nascimento da prisão. Tradução R. Ramalhete. Petrópolis: Vozes, 1987. 26ª ed.

FOUCAULT, Michel. O sujeito e o poder (1982). In: DREYFUS, Hubert L.; RABINOW, Paul. Michel Foucault, uma trajetória filosófica: para além do estruturalismo e da hermenêutica. Tradução V. Portocarreo, G. G. Carneiro. Rio de Janeiro: Forense Universitária, 2010, $2^{\mathrm{a}}$ ed., rev. Apêndice, p.273-295.

ROSSI, Paolo. O nascimento da ciência moderna na Europa. Tradução A. Angonese. Bauru: EDUSC, 2001. 